\title{
Daily Stress and Use of Aggressive Discipline by Parents during the COVID-19 Pandemic
}

\author{
Bridget Freisthler $^{1}\left[\right.$ D Jennifer Price Wolf ${ }^{2} \cdot$ Caileigh Chadwick $^{1} \cdot$ Katherine Renick $^{1}$
}

Accepted: 30 October 2021 / Published online: 27 November 2021

(c) The Author(s), under exclusive licence to Springer Science+Business Media, LLC, part of Springer Nature 2021

\begin{abstract}
To assess the relationship between stress throughout the day and aggressive discipline practices by parents during COVID-19 stay at home orders. For this study, participants took baseline survey online, then provided data three times a day (10 a.m., 3 p.m., and 9 p.m.) for 14 consecutive days using Ecological Momentary Assessment procedures. Data were collected from 323 participants, covering 9,357 observations from April 13 to May 27, 2020 in Central Ohio during stay-at-home orders due to COVID-19. Use of aggressive discipline, including corporal punishment and psychological aggression, was measured using the Dimensions of Discipline Inventory. For each higher level of stress, parents had 1.3 greater odds of using aggressive discipline. Having used aggressive discipline at baseline was related to three times greater odds of using it during the study period. Higher situational stress was associated with use of aggressive parenting. When combined with less contact with mandatory reporters, this places children at risk for abuse and neglect that may go without detection and intervention for longer time-periods. First responders and medical professionals become more important in identifying and reporting suspected child maltreatment, as this may be a child's only contact with a mandated professional for six months to a year. Well child visits, routine vaccinations, and problem-focused care are important opportunities to assess parents' stress and discipline practices that may be suggestive of abuse or neglect.
\end{abstract}

Keywords Aggressive Discipline · Ecological Momentary Assessment · COVID-19 · Pandemic · Parenting · Stress

The COVID-19 pandemic has brought devastation to people and economies across the globe (Centers for Disease Control $\&$ Prevention, 2020). Policies designed to slow the spread of the virus, including sheltering in place orders, were enacted in many countries. Although these strategies appeared to lower the number of infections, they have significant adverse consequences for mental health and other social problems

Bridget Freisthler

freisthler.19@osu.edu

Jennifer Price Wolf

Jennifer.wolf@sjsu.edu

Caileigh Chadwick

chadwick.69@osu.edu

Katherine Renick

renick.9@osu.edu

1 College of Social Work, The Ohio State University, 340C Stillman Hall, 1947 College Rd. N, Columbus, OH 43210, USA

2 School of Social Work, San Jose State University, 1 Washington Square, San Jose, CA 95112, USA
(Patrick et al., 2020; Wang et al., 2020). Parents of younger children have been particularly impacted by sheltering in place, as childcare facilities have closed and schools pivoted to remote learning during the initial lockdown period. Emerging studies suggest that parents reported high levels of stress due to COVID-19 (Hiraoka \& Tomoda, 2020; Miller et al., 2020; van Tilburg et al., 2020). High levels of parental stress could in turn negatively impact parenting (Holden \& Banez, 1996; Liu et al., 2020; Rodriguez \& Richardson, 2007).

A central mechanism by which the COVID-19 pandemic could impair parenting is through parental stress. The parenting stress model (Abidin, 1995) argues that parental stress is influenced by characteristics of the parent and child, as well as factors in the surrounding environment. Parents may be more at risk of experiencing stress than the general population, as they have unique concerns related to the pandemic such as the closure of schools and childcare (Calvano et al., 2021). Parents have reported higher levels of parenting stress compared to pre-pandemic and are more likely to report higher levels of parenting stress if they are 
more impacted by the effects of the pandemic (Calvano et al., 2021; Chung et al., 2020). Parents' perception of how challenging they find COVID-19 lockdown has been demonstrated to be significantly associated with a higher stress level (Spinelli et al., 2020).

This increase in parental perceived stress could increase the use of aggressive discipline. Under high levels of stress, as occurred during COVID-19, parents may not regulate their emotions as effectively and be prone to yell or use other types of aggressive discipline towards their children (Restubog et al., 2020). Types of aggressive parenting such as corporal punishment (i.e. physical punishment that does not rise to the threshold of abuse) and psychological aggression (i.e. threatening and demeaning a child) are both associated with actual child maltreatment and have longterm negative consequences for children (Gershoff, 2002; Gershoff \& Grogan-Kaylor, 2016; King et al., 2018; Lee et al., 2014; Masud et al., 2019; Rodriguez, 2010). Higher parental stress during the COVID-19 pandemic is associated with an increased use of harsh parenting (such as, yelled at children more often and spanked or caned children more often; Chung et al., 2020). Rodriguez et al. (2021) found that over $20 \%$ of parents reported an increase in discipline, with almost $25 \%$ reporting an increase in yelling/screaming, $12 \%$ an increase in using harsh words towards their children, and $5 \%$ spanking or hitting their children more than usual. Imran and colleagues (2020) found that parenting stress impacted parents' usual parenting behaviors, as at least 50\% reported more than the usual consequences, such as shouting, taking privileges away, or slapping their child. Stressful pandemic related factors, such as social isolation and job loss, were associated with an increase in discipline changes, including using spanking more often (Lee et al., 2021). For each additional COVID-19 related stressor experienced by a household family member, the odds of harsh psychological discipline increased by $5 \%$ and harsh physical discipline by 13\% (Connell \& Strambler, 2021).

These studies appear to be consistently showing higher rates of aggressive or harsh parenting; however, they were all conducted by asking parents to report retrospectively on their parenting behaviors and stress levels, even in longitudinal studies. This limits our ability to identify under what specific conditions parents experienced higher levels of stress that may precipitate use of aggressive discipline in real-time. In other words, previous work has not assessed whether parents were experiencing high levels of stress during the aggressive discipline event. Much remains unknown about the temporal relationships between stress and aggressive discipline during COVID-19.

This study attempts to capture nuanced temporal relationships between parent stress and parenting practices during the pandemic. The findings could help us begin to identify those situational factors that contribute to specific instances of harsh parenting. We do this by using ecological momentary assessment (EMA), a methodology that enables us to conduct repeated sampling of subjects' behaviors and experiences in real time and in their natural environments through smartphone-based applications. EMA has several advantages in collecting data on parenting during the COVID-19 pandemic. The immediacy of EMA surveys, collected daily or multiple times a day, may garner a more accurate picture of parenting behaviors. Parents may be more likely to use aggressive discipline at specific times, such as in the late afternoon or evening, due to fatigue or an accumulation of stressors. While some EMA research suggests that parenting stress is associated with variability in use of harsh parenting (Li \& Lansford, 2018), very little is known about how use of aggressive discipline changes throughout a day. Therefore, these examinations of parenting through short response windows such as those from EMA could give a more "real-world" view of parenting (Passini et al., 2014).

The length of 'stay at home' and 'shelter in place' orders during the COVID-19 pandemic, combined with massive unemployment, has led to parents spending more time at home with their children. During the initial stay at home orders, additional restrictions were enacted at the state-level, including a move to fully on-line schooling for the remainder of the 2019-2020 academic year. This provides us with a rare opportunity to understand the micro-contexts of the home environments for families, including the relationship between stress throughout the day and aggressive discipline practices (e.g., corporal punishment and psychological aggression). In our study, we examine how at-the-moment stress and COVID-19 milestones (e.g., move to all virtual schooling) is related to aggressive discipline.

\section{Methods}

\section{Study Design and Data Collection}

We conducted an EMA study with parents recruited through online venues (e.g., Craigslist, Facebook) and word of mouth to provide real-time feedback on stress levels and parenting practices. Online screening surveys assessed initial eligibility for the study. Eligibility criteria included being over 18, having a child between 2 and 12 years old, living in Central Ohio, and having a smartphone they could use for the study. We contacted eligible parents via email to schedule a call to conduct informed consent and provide more information about the study. Parents provided verbal consent over the phone where they were told the purpose of this study was to investigate how different factors including everyday stress and geographic locations affect parenting practices. Responses were confidential. Three hundred forty-two individuals consented to participate in the study during April 
13-May 7, 2020. Of those, nine did not complete any study activities, one did not complete any EMA surveys (due to their phone being incompatible with the app used to collect EMA data), and one completed only the EMA surveys but not the baseline survey. Once consented, participants were asked to take a baseline survey online, download the research app MetricWire, and enroll in the study. Participants received a $\$ 50$ gift card after those three steps. The baseline survey was conducted before respondents began the EMA surveys and provided information on demographics, parenting behaviors, and stress. EMA data on parenting during COVID-19, particularly as it relates to aggressive discipline, is limited (see Freisthler et al., 2021; Janssen et al., 2020; Price Wolf et al., 2021). Use of EMA on parenting behaviors and stress suggests that inter-parent variation in parenting behaviors across the day are high, and that these behaviors averaged across longer periods (e.g., 30 days) may miss this variation and potential exacerbating circumstances for problematic parenting (Passini et al., 2013). Brief daily surveys were administered three times a day (10 a.m., 3 p.m., and 9 p.m.) for 14 consecutive days. Participants received a push notification each time an EMA survey was active and had to record their response within four hours of the initial notification. Participants could earn an additional $\$ 100$ in incentives if they completed all 42 EMA surveys and enabled geotracking over the survey time-period. The institutional review board at The Ohio State University approved the protocols for the Central Ohio Family Life.

For our study, 9,357 EMA observations are nested within 323 individuals (see Fig. 1). Participants were asked to identify a focal child, defined as an eligible child with the most recent birthday, and responded to all parenting measures thinking about their interactions with that child. Each brief survey asked participants to rate their stress level on a scale of 1 to 10 , where they were (e.g., home, store), whether the focal child had been with them during the last survey period, and, if so, four items about parenting behaviors. Specifically, parents were asked "Since the last survey, have you parented this child in any of the following ways?" Participants were primarily mothers $(92.6 \%)$, married $(86.4 \%)$ with at least a college diploma (76.8\%). The average age of the focal child was 6.2 years old (standard deviation $=3.07$ ), with over half of the children being male (56.3\%) and White (78.0\%). (Table 1)

\section{Survey Instrument}

Our dependent variable is the use of aggressive discipline throughout the day. This was assessed using the Dimensions of Discipline Inventory (DDI; Straus \& Fauchier, 2011),

Fig. 1 Flow Diagram of Observation Selection Procedures

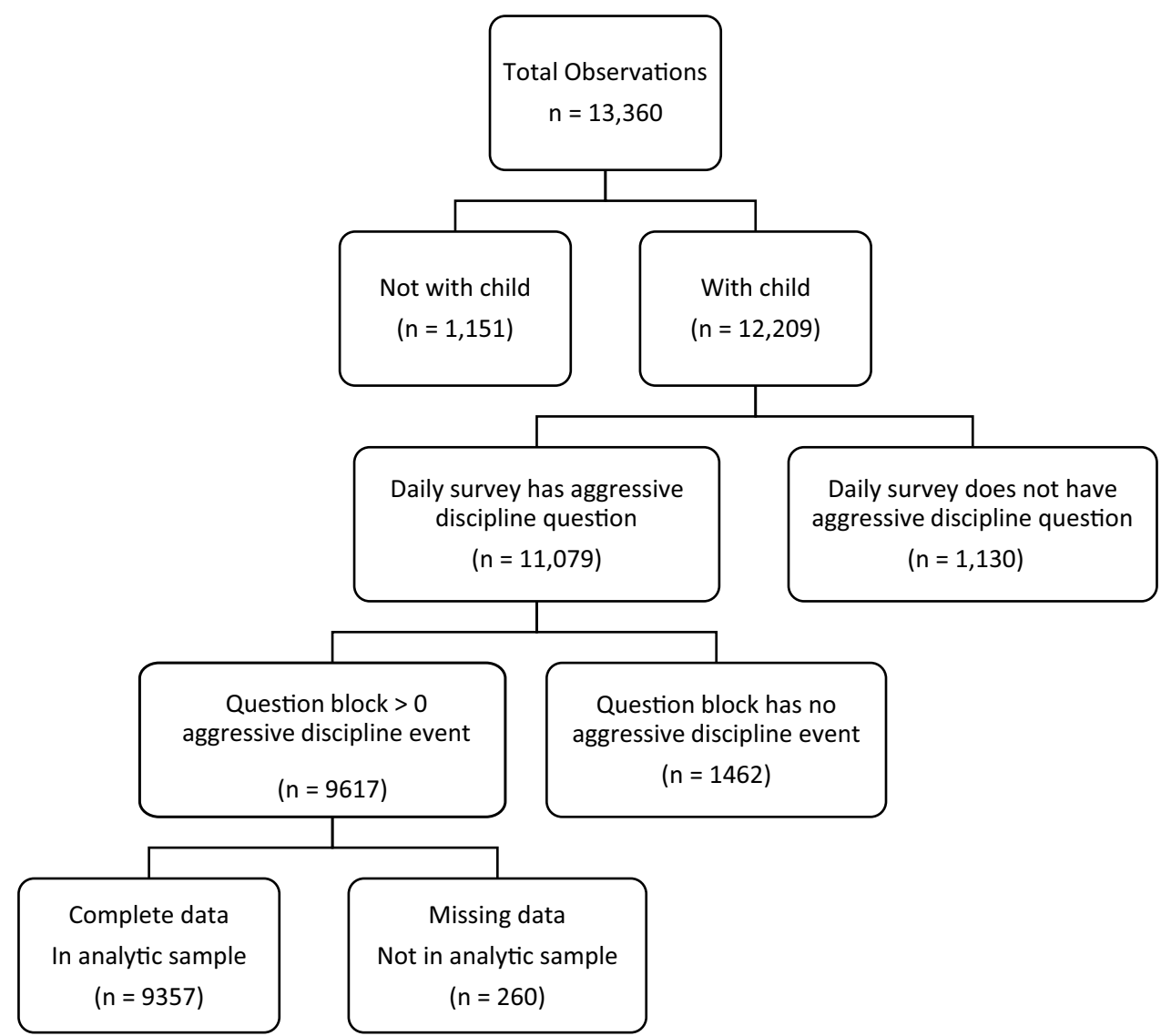


Table 1 Characteristics of Analytic Sample for 332 Study Participants

\begin{tabular}{|c|c|}
\hline & Mean (SD) or \% (n) \\
\hline \multicolumn{2}{|l|}{ Dependent Variable (Level 1) } \\
\hline \multicolumn{2}{|l|}{ Aggressive Parenting } \\
\hline Yes & $4.5(423)$ \\
\hline No & $95.5(8934)$ \\
\hline \multicolumn{2}{|l|}{ Observation-Level Variables (Level 1) } \\
\hline Stress & $3.26(2.13)$ \\
\hline \multicolumn{2}{|l|}{ Time of Day } \\
\hline 10:00 a.m & $33.5(3132)$ \\
\hline 3:00 p.m & $32.0(2990)$ \\
\hline 9:00 p.m & $34.6(3235)$ \\
\hline \multicolumn{2}{|l|}{ Parent Characteristics } \\
\hline \multicolumn{2}{|l|}{ Parent Biological Sex } \\
\hline Female & $92.6(299)$ \\
\hline Male & $7.4(24)$ \\
\hline Parent Age & $37.43(5.91)$ \\
\hline \multicolumn{2}{|l|}{ Marital Status } \\
\hline $\begin{array}{l}\text { Married or Living in a Marriage-Like } \\
\text { Relationship }\end{array}$ & 86.4 (279) \\
\hline Single/Widowed/Divorced & $13.6(44)$ \\
\hline \multicolumn{2}{|l|}{ Parent Education } \\
\hline$\leq$ High School Diploma & $2.8(9)$ \\
\hline Some College & $20.4(66)$ \\
\hline Bachelor Degree & $34.7(112)$ \\
\hline Graduate Degree & $42.1(136)$ \\
\hline \multicolumn{2}{|l|}{ Child Characteristics } \\
\hline \multicolumn{2}{|l|}{ Child Biological Sex } \\
\hline Female & $43.7(141)$ \\
\hline Male & $56.3(182)$ \\
\hline Focal Child Age & $6.18(3.07)$ \\
\hline \multicolumn{2}{|l|}{ Child Race/Ethnicity } \\
\hline Caucasian/White & $78.0(252)$ \\
\hline African American/Black & $12.1(39)$ \\
\hline Other Race or Ethnicity & $9.9(32)$ \\
\hline \multicolumn{2}{|l|}{ Family Characteristics } \\
\hline Number of Children & $2.15(0.96)$ \\
\hline
\end{tabular}

which included 13 punitive and 13 non-punitive measures. We ask the entire scale during the on-line administration of the baseline survey. The aggressive discipline scale is comprised of eight items that are a subsect of the thirteen punitive measures. Four items ask about using corporal punishment (e.g., Did you shake or grab this child to get their attention?), while an additional four asked about psychological aggression (e.g., Did you try to make this child feel ashamed or guilty?). These items are similar to the scales of the same name in the Conflict Tactics Scale, Parent-Child version (Straus et al., 1998). For this administration of the DDI, we used response categories of never, less than once a month, a few times a month, a few times a week, several times a week, and daily. We created a dichotomous variable, where categories a few times a week, several times a week, and daily indicated use of aggressive discipline to mimic the frequency of the events over the 14-day EMA study. Cronbach's alpha for the aggressive discipline scale of the DDI was 0.56 .

We asked four parenting behaviors from the DDI during each administration of the assessment for the EMA surveys. Of the four parenting behaviors presented, two were non-punitive parenting practices (e.g., demonstrate the right thing to do), and two were punitive practices (e.g., shout or yell at child). Discipline behaviors were randomized by punitive and non-punitive status. The first two non-punitive and punitive disciplines were included in a question block. We conducted this process four times until we 42 blocks of questions (one for each EMA). Those 42 blocks of questions were then randomized so that they were asked at different times of days for each participant. Parents did not receive the same questions each time and did not have the same ordering of questions as other parents in the study. Participants were to check which, if any, of the four discipline practices they had used since the last survey. For this study, we focus on the eight items that comprise the aggressive discipline scale. Over the course of the study, 38 of the 42 survey block administrations of the brief survey contained at least one aggressive discipline question for this study. We minimized reactivity, defined as changing behavior when being observed, by asking different parenting items at each thrice daily assessment.

We assessed global baseline levels of stress during the online survey and situational stress throughout the day using the EMA. The 10-item Perceived Stress Scale (Cohen, 1983) used in the baseline survey is designed to assess global levels of stress during the previous month. Responses included never, almost never, sometimes, fairly often, and very often. When needed, responses were reverse coded and all items were summed. This measure showed excellent internal consistency reliability $(\alpha=0.90)$. Stress was measured for each EMA observation period using a ten-point scale, where one was low stress and ten indicated high stress. During the EMAs, this item is used to assess situational stress. This item was compared to results of the 10-item Perceived Stress Scale in a study conducted by the American Psychological Association (American Psycholocial Association, 2014). There was a correlation of 0.682 between the two measures; indicating strong agreement between the two measures (American Psychological Association, 2014). The use of EMA to record this information means we can link the stress-level of the parent to the use of a specific aggressive discipline technique that occurred during the same time frame. 
We included the dates of two stay-at-home milestones for Ohio to assess how these may have affected the use of aggressive discipline. On April 20, 2020, the Ohio governor announced that children in grades kindergarten through twelfth grades would be attending school virtually through the end of the 2019-2020 academic year. Most retail businesses were allowed to open beginning on May 12, 2020 with specific social distancing and cleaning restrictions, providing families with greater opportunities to be outside of the home. Finally, we included indicators for the calendar weeks when the EMAs were completed, as we were concerned that the cumulative stress of stay-at-home orders would translate to more use of aggressive discipline for parents participating later in the study. We also included dummy variables representing the trigger time for the survey (e.g., 10 a.m.).

We also included control variables in our study (from the baseline survey), including parent and child biological sex, child age, child race/ethnicity (recoded as White, Black, or Other), number of children in the household, parent education level (recoded as high school graduate or less, some college (includes those with Associate degrees), Bachelor degrees, or graduate degrees), and marital status.

\section{Data Analysis}

Data were analyzed using overdispersed hierarchical generalized linear models with logit link function using HLM 7.01 (Raudenbush, Bryk, \& Congdon, 2013). Observations of aggressive discipline (Level 1) were nested within individuals (Level 2) to assess within person variation of stress and parenting. On average, each individual had 29 observations for the aggressive discipline question blocks. Multilevel models controlled for intraclass correlations that exist when using repeated measures for a person. In our study, intraclass correlation was measured at 0.673 .

Missing data was minimal across all forms of data collection. $95.8 \%$ of all EMA surveys were completed $(13,361$ out of a possible 13,944). Of the 13,361 EMAs completed, $33.5 \%$ were completed during the 10 a.m. assessment, $33.3 \%$ were completed at the 3 p.m. assessment, and $33.2 \%$ were completed at the 9 p.m. assessment. We also had incredible compliance with our baseline surveys as well. Of the 332 individuals who completed the initial baseline survey, $97.3 \%$ $(\mathrm{n}=323)$ provided complete baseline data.

\section{Results}

At the individual occurrence level (Level 1), higher stress levels during the EMAs throughout the day were related to higher odds for using aggressive discipline in Model 1 (see Table 2). Brief surveys that were triggered at 3 p.m. and
9 p.m. were related to more use of aggressive discipline, compared to the 10 a.m. surveys. Parents who reported using aggressive discipline at least a few times a week in the baseline survey had about a three-fold greater odds of reporting use of aggressive discipline during the brief surveys. Scores from the Perceived Stress Scale were not related to situational use of aggressive discipline. Thus, it appears that situational stress is a more important factor in predicting use of aggressive discipline than more generalized stress. Model 2 (in Table 2) includes sociodemographic characteristics for the participant, focal child, and family. In Model 2, we see similar results to Model 1 . We also found that parents who were married or living in a marriage-like relationship were more likely to report use of aggressive discipline. No other sociodemographic variables were related to use of daily aggressive discipline behaviors.

In Table 3 Model 3, we added the COVID-19 specific dates to assess changes in use of aggressive discipline by those milestones. Although both dates had odds ratios greater than 1.0, the confidence intervals show that these are not statistically significant. Further, our indicator variables that denote the weeks the EMAs were completed were also not statistically significant. Our findings in Model 3 mirror those in Model 2, even after adding these milestones. We conducted additional analyses that examined whether stress at the previous time period was related to current use of aggressive discipline. In our model with stress for both the current and previous time periods, stress at the previous time period stress was not related to aggressive discipline; current time period stress remained positively related to use of aggressive discipline. In the second additional analysis, we only included previous time period stress, which was statistically significant and positive.

\section{Discussion}

Our study sought to assess levels of stress throughout the day and its effects on use of aggressive discipline during the COVID-19 pandemic. By using EMA, we collected realtime data of parents' use of discipline and stress, reducing recall bias, and allowing us to study behaviors over time. Higher levels of stress throughout the day were related to more use of aggressive discipline, particularly during the afternoon and evening hours while COVID-19 'stay at home' orders were in place for Ohio. Our findings are similar to previous work showing higher stress during COVID19 is associated with harsh parenting (Connell \& Strambler, 2021, Lee et al., 2021 Rodriguez et al., 2021).

Compared to other natural disasters, which have often involved the physical displacement of families, social distancing as a result of COVID-19 has resulted in children and parents being forced to remain at home, where they 
Table 2 Relationship between 9,357 Daily Stress Observations and 323 Participant Characteristics on Use of Aggressive Discipline

\begin{tabular}{|c|c|c|c|c|}
\hline & \multicolumn{2}{|l|}{ Model 1} & \multicolumn{2}{|l|}{ Model 2} \\
\hline & Odds Ratio & 95\% Confidence Interval & Odds Ratio & 95\% Confidence Interval \\
\hline Constant & 0.004 & $(0.002,0.07)^{* *}$ & .001 & $(0.000,0.003)^{* *}$ \\
\hline \multicolumn{5}{|l|}{ Observation-Level Variables (Level 1) } \\
\hline Stress & 1.318 & $(1.265,1.374)^{* *}$ & 1.327 & $(1.272,1.384)^{* *}$ \\
\hline \multicolumn{5}{|l|}{ Time of Day (reference: 10 a.m.) } \\
\hline 3:00 p.m & 1.280 & $(1.043,1.571)^{*}$ & 1.280 & $(1.044,1.570)^{*}$ \\
\hline 9:00 p.m & 1.692 & $(1.390,2.059)^{* *}$ & 1.697 & $(1.395,2.064)^{* *}$ \\
\hline \multicolumn{5}{|l|}{ Individual Characteristics (Level 2) } \\
\hline Perceived Stress Scale Score & 1.012 & $(0.987,1.038)$ & 1.016 & $(0.990,1.042)$ \\
\hline Use Aggressive Discipline Weekly & 3.069 & $(2.208,4.266)^{* *}$ & 2.960 & $(2.113,4.146)^{* *}$ \\
\hline Female Caregiver & & & 1.294 & $(0.642,2.609)$ \\
\hline \multicolumn{5}{|l|}{ Marital Status reference: Single/Widowed/Divorced) } \\
\hline Married or living in marriage-like relationship & & & 1.927 & $(1.104,3.363)^{*}$ \\
\hline \multicolumn{5}{|l|}{ Parent Education (reference: Some college or less) } \\
\hline Bachelor's Degree & & & 1.261 & $(0.800,1.986)$ \\
\hline Graduate Degree & & & 1.283 & $(0.828,1.988)$ \\
\hline Male child & & & 1.186 & $(0.854,1.646)$ \\
\hline Focal Child Age & & & 1.006 & $(0.951,1.064)$ \\
\hline \multicolumn{5}{|l|}{ Child Race/Ethnicity (reference: White) } \\
\hline African American/Black & & & 0.940 & $(0.564,1.565)$ \\
\hline Other Race or Ethnicity & & & 1.262 & $(0.744,2.171)$ \\
\hline Number of Children & & & 1.071 & $(0.894,1.284)$ \\
\hline
\end{tabular}

${ }^{* *} \mathrm{p}<.001$

$*$ p $<.05$

might also be expected to conduct paid work. In many areas, schools and daycares closed, resulting in more exposure between potentially stressed parents and children. Although they spent greater time together, the uncertainty of the pandemic could place parents into "survival mode" whereby they may become over-reactive to child demands and increase their use of punitive parenting such as psychological aggression and corporal punishment (SelfBrown et al., 2013). Children may have negative moods due to frustration with online schooling or sheltering in place, which could increase parenting hassles and subsequent stress levels (Walerius et al., 2016).

Notably, if schools had remained open during this period, many parents would not have spent significant amounts of time with their children between the morning and mid-afternoon EMA surveys. By asking parents to stay at home with their children, acting as parents, teachers, and employees, while often facing financial distress, has surely increased the stress they have experienced. This situational stress may result in greater use of aggressive discipline by parents in the study, particularly later in the day. Neither of our milestone dates were related to changes in use of aggressive discipline. These macro-level factors may be less important to the discipline strategies used by parents compared to the stress a parent is feeling in the moment.

Parents who, at baseline, reported using aggressive discipline at least a few times a week had a greater likelihood of reporting use of greater discipline during the EMA surveys. However, stress levels assessed at baseline were not related to subsequent EMA observations of aggressive discipline. Situational stress appears to be more important when assessing a child's risk for experiencing aggressive discipline. Married parents also had a greater odds of using aggressive discipline. This result was unexpected. Possible explanations for this findings could be that single parents may have had more experience balancing child care demands with work or married couples may have conflict about who and how much each parent should care for their children spilling over into parenting behaviors. We do know that mothers have a disproportionate effects and household burden experienced by mothers (as opposed to fathers) during the pandemic (Collins et al., 2020; Kerr et al., 2021). Our sample is largely comprised of women, thus what we may be seeing is increased contact of women with their children in married relationships may mean mothers are using all parenting techniques more often, including aggressive discipline. 
Table 3 Relationship between 9,357 Daily Stress Observations and 323 Participant

Characteristics on Use of Aggressive Discipline during COVID Stay-at-Home Orders

\begin{tabular}{|c|c|c|}
\hline & \multicolumn{2}{|l|}{ Model 3} \\
\hline & Odds Ratio & 95\% Confidence Interval \\
\hline Constant & 0.001 & $(<0.001,0.004)^{* *}$ \\
\hline \multicolumn{3}{|l|}{ Observation-Level Variables (Level 1) } \\
\hline Stress & 1.338 & $(1.282,1.396)^{* *}$ \\
\hline \multicolumn{3}{|l|}{ Time of Day (reference: 10 a.m.) } \\
\hline 3:00 p.m & 1.281 & $(1.044,1.570)^{*}$ \\
\hline 9:00 p.m & 1.700 & $(1.397,2.067)^{* *}$ \\
\hline \multicolumn{3}{|l|}{ Individual Characteristics (Level 2) } \\
\hline Perceived Stress Scale Score & 1.015 & $(0.989,1.041)$ \\
\hline Use Aggressive Discipline Weekly & 3.007 & $(2.136,4.234)^{* *}$ \\
\hline Female Caregiver & 1.281 & $(0.627,2.671)$ \\
\hline \multicolumn{3}{|l|}{ Marital Status reference: Single/Widowed/Divorced) } \\
\hline Married or living in marriage-like relationship & 1.946 & $(1.105,3.426)^{*}$ \\
\hline \multicolumn{3}{|l|}{ Parent Education (reference: Some college or less) } \\
\hline Bachelor's Degree & 1.216 & $(0.765,1.932)$ \\
\hline Graduate Degree & 1.246 & $(0.798,1.945)$ \\
\hline Male child & 1.192 & $(0.854,1.9663)$ \\
\hline Focal Child Age & 1.006 & $(0.950,1.065)$ \\
\hline \multicolumn{3}{|l|}{ Child Race/Ethnicity (reference: White) } \\
\hline African American/Black & 0.962 & $(0.573,1.614)$ \\
\hline Other Race or Ethnicity & 1.288 & $(0.753,2.203)$ \\
\hline Number of Children & 1.064 & $(0.885,1.279)$ \\
\hline \multicolumn{3}{|l|}{ COVID-19 Orders } \\
\hline April 20, 2020: School Virtual & 1.176 & $(0.735,1.880)$ \\
\hline May 12, 2020: Retail Businesses Open & 1.335 & $(0.617,2.887)$ \\
\hline \multicolumn{3}{|l|}{ Week of Assessment (reference: April 12, 2020) } \\
\hline Week of April 19 & 0.679 & $(0.356,1.294)$ \\
\hline Week of April 26 & 0.713 & $(0.359,1.418)$ \\
\hline Week of May 3 & 1.015 & $(0.504,2.047)$ \\
\hline Week of May 10 & 0.675 & $(0.284,1.606)$ \\
\hline Week of May 17 & 0.598 & $(0.120,2.969)$ \\
\hline
\end{tabular}

Many schools remained virtual or in a hybrid mode for an extended period of time and some families who lost their jobs are likely forgoing using child care centers. Thus, contact with mandated reporters for child abuse and neglect continues to be lower than usual (Brown et al., 2021). First responders and medical professionals become more important in identifying and reporting suspected child maltreatment, as this may be a child's only contact with a mandated professional for six months to a year. Well child visits, routine vaccinations, and problem-focused care are important opportunities to assess parents' stress and discipline practices that may be suggestive of abuse or neglect. Medical professionals can also acknowledge parents' stress and provide them with techniques on how to manage and reduce it. Training may be needed on how to identify abuse or neglect during virtual interactions for physicians, teachers, school counselors, and mental health professionals (Thomas et al., 2020). Child welfare officials should be ready for a possible increase in reporting of child abuse and neglect as children return to in-person school and activities.

\section{Limitations}

Our study is a convenience sample of primarily mothers who live in central Ohio. Our study also includes a majority of participants with graduate degrees. Thus, the generalizability of our study may be limited. However, as we found that stress is related to use of aggressive parenting in a population with arguably more financial resources during the time of COVID-19, parents with the lack of economic and social resources may be at even greater risk for using harsh 
parenting during this stressful time. These findings should also be considered as a lower bound for the estimates of aggressive discipline. We did not ask aggressive discipline questions during every brief survey and only asked the parent to report on these behaviors for a focal child. Further, as we randomized the order of questions, some aggressive discipline items were asked early in the day when they might be much less likely to occur (e.g., send a child home to bed without a meal). The act of asking parents about discipline procedures on a regular schedule may cause parents to reflect on or change their own parenting to use fewer aggressive discipline techniques. The psychometric properties for the aggressive discipline scale is fair, partly due to the low occurrence of some of the corporal punishment items. Finally, parents were asked to denote parenting behaviors that may have occurred since the last survey. Some parents may have completed the EMA right when it was triggered while others may have waited until the end of the EMA survey time period. The latter group would have had more time in which to have used some of the parenting behaviors. In other words, parents were not reporting based on the same unit of time.

\section{Conclusions}

The effects of COVID-19 on child abuse and neglect will likely not be known for months to years, when we have a chance to examine administrative data sets. For now, many child welfare agencies are concerned that lower levels of referrals for investigations of child abuse are due to decreased surveillance by mandatory reporters (Brown et al., 2021). Our study shows that higher situational stress increases the use of aggressive parenting. When combined with less contact with mandatory reporters, this places children at risk for abuse and neglect that may go without detection and intervention for longer time-periods.

Acknowledgements Funded by the Ohio State University Office of Research's COVID-19 seed grant program.

\section{References}

Abidin, R.R. (1995). Parenting stress index, third edition: Professional manual. Psychological Assessment Resources; Odessa, FL.

American Psychological Association (2014). Stress in America ${ }^{T M}$ : Are Teens Adopting Adults' Stress Habits?. https://www.apa.org/ news/press/releases/stress/2013/stress-report.pdf. Accessed 29 May 2020.

Brown, S.M., Orsi, R., Chen, P.C.B., Everson, C.L. \& Fluke, J. (2021). The impact of the COVID-19 Pandemic on Child Protection System referrals and responses in Colorado, USA. Child Abuse \& Neglect. Online early. https://doi.org/10.1177\%2F1077559521101 2476
Calvano, C., Engelke, L., Di, Bella. J., Kindermann, J., Renneberg, B., \& Winter, S. M. (2021). Families in the covid-19 pandemic: parental stress, parent mental health and the occurrence of adverse childhood experiences-results of a representative survey in germany. European Child \& Adolescent Psychiatry, 2021 Mar 01. https://doi.org/10.1007/s00787-021-01739-0

Centers for Disease Control and Prevention. (2020). United States COVID-19 Cases and Deaths by State. Retrieved from: https:// covid.cdc.gov/covid-data-tracker/\#cases_casesper100klast7days

Chung, G., Lanier, P., \& Wong, P. Y. J. (2020). Journal of Family Violence. Online early: https://doi.org/10.1007/ s10896-020-00200-1

Cohen, S., Kamarck, T., \& Mermelstein, R. (1983). A global measure of perceived stress. Journal of Health and Social Behavior, 24, 386-396.

Collins, C., Landivar, L. C., Ruppanner, L., \& Scarborough, W. J. (2021). COVID-19 and the gender gap in work hours. Gender, Work, and Organization, 28(S1), 101-112. https://doi.org/10. 1111/gwao.12506

Connell, C. M., \& Strambler, M. J. (2021). Experiences with COVID19 stressors and parents' use of neglectful, harsh, and positive Parenting Practices in the Northeastern United States. Child Maltreatment, 10775595211006464. https://doi.org/10.1177/10775 595211006465

Freisthler, B., Gruenwald, P. J., Tebben, E., Shockley McCarthy, K., \& Price Wolf, J. (2021). Understanding at-the-moment stress for parents during COVID-19 stay-at-home restrictions. Social Science and Medicine, 279, 114025. https://doi.org/10.1016/j.socsc imed.2021.114025

Gershoff, E. (2002). Corporal punishment by parents and associated child behaviors and experiences: A meta-analytic and theoretical review. Psychological Bulletin, 128, 530-579.

Gershoff, E., \& Grogan-Kaylor, A. (2016). Spanking and child outcomes: Old controversies and new meta-analyses. Journal of Family Psychology, 30(4), 453-469. https://doi.org/10.1037/ fam0000191

Hiraoka, D., \& Tomoda, A. (2020). Relationship between parenting stress and school closures due to the COVID-19 pandemic. Psychiatry and Clinical Neurosciences, 74, 497-498. https://doi.org/ 10.1111/pen. 13088

Holden, E. W., \& Banez, G. A. (1996). Child abuse potential and parenting stress within maltreatment families. Journal of Family Violence, 11, 1-12.

Imran, N., Imran Sharif, M., Iqtadar, S., Waqar Azeem, M., Aamer, I., Liaqat, S., \& Malik, S. (2020). 51.10 parental stress and parenting in times of the covid-19 pandemic in pakistan. Journal of the American Academy of Child \& Adolescent Psychiatry, 59(10). S254.

Janssen, L.H.C., Kullberg, M-L.J., Verkuil, B., van Zwieten, N., Wever, M.C.M., van Houtum, L.A.E.M., Wentholt, W.G.M., \& Elzinga, B.M. 2020 Does the COVID-19 pandemic impact parents and adolescents' well-being? An EMA-study on daily affect and parenting. PLoS ONE, 15 (10): e0240962. https://journals.plos.org/ plosone/article?id=https://doi.org/10.1371/journal.pone.0240962

Kerr, M.L., Rasmussen, H.F., Fanning, K.A., \& Braaten, S.M. (2021). Parenting during COVID-19: A study of parents' experiences across gender and income levels. Online early, Family Relations. https://onlinelibrary.wiley.com/doi/full/https://doi.org/10.1111/ fare. 12571

King, A. R., Ratzak, A., Ballantyne, S., Knutson, S., Russell, T. D., Pogalz, C. R., \& Breen, C. M. (2018). Differentiating corporal punishment from physical abuse in the prediction of lifetime aggression. Aggressive Behavior, 44(3), 306-315. https://doi.org/ 10.1002/ab.21753

Lee, S. J., Grogan-Kaylor, A., \& Berger, L. M. (2014). Parental spanking of 1-year-old children and subsequent child protective services 
involvement. Child Abuse \& Neglect, 38, 875-883. https://doi.org/ 10.1016/j.chiabu.2014.01.018

Lee, S. J., Ward, K. P., Lee, J. Y., \& Rodriguez, C. M. (2021). Parental social isolation and child maltreatment risk during the COVID-19 pandemic. Journal of Family Violence, 2020. https://doi.org/10. 1007/s 10896-020-00244-3

Li, J. J., \& Lansford, J. E. (2018). A smartphone-based ecological momentary assessment of parental behavioral consistency: Associations with parental stress and child ADHD symptoms. Developmental Psychology, 54(6), 1086-1098. https://doi.org/10. 1037/dev0000516

Liu, S-W., Zhai, F., \& Gao, Q. (2020). Parental stress and parenting in Chinese immigrant families: The mediating role of social support. Child \& Family Social Work. Advance online publication. https:// doi.org/10.1111/cfs.12734

Masud, H., Ahmad, M. S., Cho, K. W., \& Fakhr, Z. (2019). Parenting styles and aggression among young adolescents: A systematic review of literature. Community Mental Health Journal, 55(6), 1015-1030. https://doi.org/10.1007/s10597-019-00400-0

Miller, J. J., Cooley, M. E., \& Mihalec-Adkins, B. P. (2020). Examining the Impact of COVID-19 on Parental Stress: A Study of Foster Parents. Child \& Adolescent Social Work Journal. Advance online publication. https://doi.org/10.1007/s10560-020-00725-w

Passini, C., Pihet, S., \& Favez, N. (2014). Assessing specific discipline techniques: A mixed-methods approach. Journal of Child and Family Studies, 23, 1389-1402. https://doi.org/10.1007/ s10826-013-9796-0

Passini, C., Pihet, S., Favez, N., \& Schoebi, D. (2013). Assessment of parental discipline in daily life. Journal of Family Psychology, 27(2), 324-329. https://doi.org/10.1037/a0031504

Patrick, S. W., Henkhaus, L. E., Zickafoose, J. S., Lovell, K., Halvorson, A., Loch, S., ... Davis, M. M. (2020). Well-being of Parents and Children During the COVID-19 Pandemic: A National Survey. Pediatrics, 146(4). https://doi.org/10.1542/peds.2020-016824

Price Wolf, J., Freisthler, B., \& Chadwick, C. (2021). Stress, alcohol use, and punitive parenting during the COVID-19 pandemic. Child Abuse and Neglect, 117, 105090. https://doi.org/10.1016/j. chiabu.2021.105090

Raudenbush, S. W., Bryk, A. S., Congdon, R. T. (2013). HLM 7.01 for Windows [Computer software] (Version 5). Skokie, IL: Scientific Software International.

Restubog, S. L. D., Ocampo, A. C. G., \& Wang, L. (2020). Taking control amidst the chaos: Emotion regulation during the COVID-19 pandemic. Journal of Vocational Behavior, 119, 103440. https:// doi.org/10.1016/j.jvb.2020.103440

Rodriguez, C. M. (2010). Parent-child aggression: Association with child abuse potential and parenting styles. Violence \& Victims, 25(6), 728-741.
Rodriguez, C. M., Lee, S. J., Ward, K. P., \& Pu, D. F. (2021). The perfect storm: Hidden risk of child maltreatment during the covid-19 pandemic. Child Maltreatment, 26(2), 139-151. https://doi.org/10. 1177/1077559520982066

Rodriguez, C. M., \& Richardson, M. J. (2007). Stress and anger as contextual factors and preexisting cognitive schemas: Predicting parental child maltreatment risk. Child Maltreatment, 12(4), 325-337. https://doi.org/10.1177/1077559507305993

Self-Brown, S., Anderson, P., Edwards, S., \& McGill, T. (2013). Child maltreatment and disaster prevention: A qualitative study of community agency perspectives. Western Journal of Emergency Medicine, 14(4), 401-407. https://doi.org/10.5811/westjem.2013.2. 16206

Straus, M. A., Hamby, S. L., Finkelhor, D., Moore, D. W., \& Runyan, D. (1998). Identification of child maltreatment with the parentchild conflict tactics scales: Development and psychometric data for a national sample of American parents. Child Abuse \& Neglect., 22(4), 249-270.

Straus, M. A., \& Fauchier, A. (2011). Manual for the Dimensions of Discipline Inventory (DDI). Journal of Psychopathology and Behavioral Assessment. https://doi.org/10.1037/t37478-000

Thomas, E. Y., Anurudran, A., Robb, K., \& Burke, T. F. (2020). Spotlight on child abuse and neglect response in the time of COVID19. Lancet Public Health, 5(7). https://doi.org/10.1016/S24682667(20)30143-2

van Tilburg, M. A. L., Edlynn, E., Maddaloni, M., van Kempen, K., Díaz-González de Ferris, M., \& Thomas, J. (2020). High Levels of Stress Due to the SARS-CoV-2 Pandemic among Parents of Children with and without Chronic Conditions across the USA. Children (basel, Switzerland), 7(10), 193. https://doi.org/10.3390/ children7100193

Walerius, D., Fogleman, N., \& Rosen, P. (2016). The role of ADHD and negative emotional lability in predicting changes in parenting daily hassles. Journal of Child and Family Studies, 25(7), 2279-2291. https://doi.org/10.1007/s10826-016-0381-1

Wang, C., Pan, R., Wan, X., Tan, Y., Xu, L., Ho, C. S., \& Ho, R. C. (2020). Immediate psychological responses and associated factors during the inital state of the 2019 coronavirus disease (COVID19) epidemic among the general population in China. 17, 5 . https://doi.org/10.3390/ijerph17051729

Publisher's Note Springer Nature remains neutral with regard to jurisdictional claims in published maps and institutional affiliations. 